\title{
Experimental investigation of desert cooler performance using four different cooling pad materials
}

\author{
Vivek W. Khond \\ G.H. Raisoni College of Engineering, Nagpur \\ Email: vivekkhond@yahoo.co.in
}

\begin{abstract}
Evaporative cooling is a very common form of cooling buildings for thermal comfort since it is relatively cheap and requires less energy than many other forms of cooling. However evaporative cooling requires an abundant water source as an evaporate, and is only efficient when the relative humidity is low, restricting its effective use to dry climates. Traditionally, evaporative cooler pads consist of excelsior (wood wool) inside containment net. Padding media plays a large part in cooling efficiency and water consumption. This paper investigate a performance of Desert Cooler using four different pad materials in terms of cooling efficiency ,water consumption and air velocity. Pads of Stainless steel wire mesh, coconut coir, Khus and Wood wool were fabricated and tested using a laboratory-scale experimental arrangement. Maximum water consumption was observed in wood wool pad $(0.24 \mathrm{Lit} / \mathrm{min})$. Coconut coir $(0.134 \mathrm{Lit} / \mathrm{min})$ and Khus pad (0.21 Lit/min) also shown less water consumption rate as compared to conventional wood wool pad. Minimum water consumption was observed in Stainless steel wire mesh pad $(0.066 \mathrm{Lit} / \mathrm{min})$ at same fan speed. Stainless steel wire mesh pad $(4.5 \mathrm{~m} / \mathrm{s})$ and coconut coir pad $(5.2 \mathrm{~m} / \mathrm{s})$ shown higher air velocity which provides proper air distribution in room while Wood wool pad $(4 \mathrm{~m} / \mathrm{s})$ and Khus pad $(3.4 \mathrm{~m} / \mathrm{s})$ were shown lower velocity. Maximum and minimum cooling efficiency were found in wood wool pad and Stainless steel wire mesh pad.
\end{abstract}

Keywords : Cooling pads, Cooling efficiency, desert cooler, stainless steel material pad etc.

\section{INTRODUCTION:}

Civilizations throughout the ages have found ingenious ways to combat the heat in their region. An earlier form of air cooling, the wind catcher, was invented in Persia (Iran) thousands of years ago in the form of wind shafts on the roof, which caught the wind and passed it through water and blew the cooled air into the building.[1] Nowadays Iranians have changed the wind catcher into an evaporative cooler and use it widely. Meeting demand for electric power during peak periods in the summer is a major problem for most utilities in the fast-growing India. From the points of view of both demand on the grid and cost to the homeowner, it would be best to install whole-house, energy-efficient evaporative coolers rather than unitary air conditioners.

Evaporative cooling has many benefits and advantages over other forms of cooling.

It is one of the healthiest ways to cool your home because it uses clean fresh air to replace the air in your home many times an hour. The air inside your house is never re-circulated which means that smells and allergens are expelled.
Based on a totally natural process of air cooled by water means it won't dry out the air, or irritate your Skin, throat or eyes. Doors can be left open allowing you to enjoy the summer and an outdoor lifestyle. Evaporative cooling is also an inexpensive cooling option. It is up to $50 \%$ cheaper to install and seven times cheaper to run than refrigerated cooling. Since Evaporative cooling uses less electricity than other forms of cooling it is kinder to our environment as its greenhouse gas contribution is a lot lower. R. Rawangkul et al. were fabricated two small coconut coir pads of different configurations and tested using a laboratory-scale experimental arrangement. Results show that the cooling efficiency of the manufactured coconut coir evaporative cooling pad was fairly good (about 50\%) and close to that of the commercial paper pad (about 47\%)[1]. Faleh AlSulaiman et al. evaluated the performance of three natural fibers to be used as wetted pads in evaporative cooling. The chosen fibers are date palm fibers (stem), jute and luffa. As a reference, a widely used commercial wetted pad is chosen. The results show that the average cooling efficiency is highest for 
jute at $62.1 \%$, compared to $55.1 \%$ for luffa fibers, $49.9 \%$ for the reference commercial pad and $38.9 \%$ for date palm fiber [4].In present work, performance analysis of desert cooler was evaluated using Stainless steel wire mesh pad, Coconut coir pad, Khus pad and wood wool pad and compared in terms of cooling efficiency, water consumption rate and air velocity.

\section{MATERIALS AND METHOD:}

Experimental Desert cooler unit consists of a cubical box of sheet metal containing large vertical filter pads, an electric-motor-driven fan, a water pump, a water distribution system, and a water sump at the bottom as shown in fig 1 . The fan draws in warm outside air through the wetted media, cooling the air. The water pump lifts the water from the sump through the distribution system to the top of the pads from where it trickles down by gravity back to the water sump. The cooled air is then delivered either directly through a grille into a single room or into a duct distribution system. Outlet section contains DBT/WBT sensor for outlet air condition measurement. Hot wire type anemometer is placed at the centre of the duct for air velocity measurement. Maximum cooling efficiency was found in wood wool and Khus pad materials.

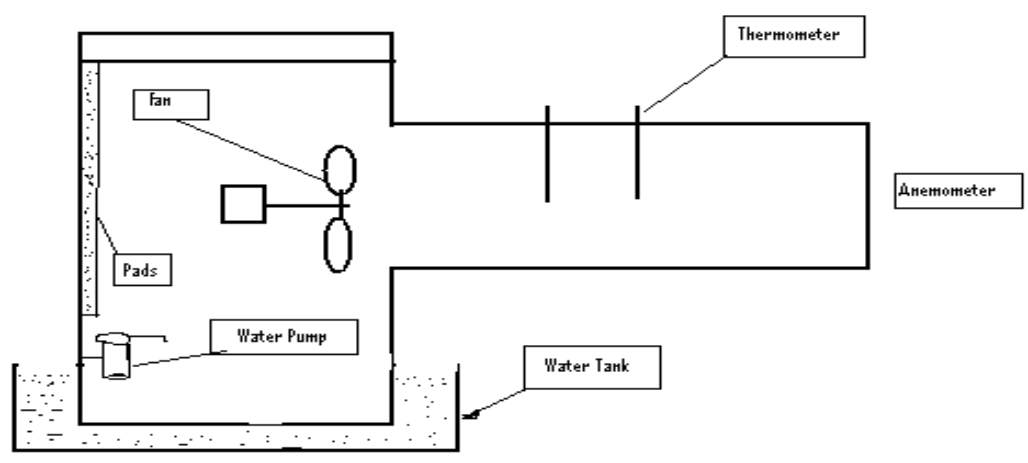

Fig 1: Experimental Setup

\section{RESULTS AND DISCUSSION:}

Experimentation was conducted under varying speed of fan, and parameters like water consumptions, cooling efficiency, and air velocity were measured. Fig-2 revealed that water consumption rate for stainless steel wire mesh pad is very low as compared to other Pads.

Maximum water consumption was observed in wood wool pad. Coconut coir and Khus pad also shown less water consumption rate as compared to conventional wood wool pad. At fan speed, water consumption was lower for all pad materials.

Fig 3 shows a variation of fan speed vs. cooling efficiency of various pad materials. Maximum cooling efficiency was found in wood wool and Khus pad materials. Stainless steel wire materials pad shows poor cooling efficiency as compared to other pad materials but can be use where relative humidity was higher. As fan speed decreases, cooling efficiency of all pad materials increases.

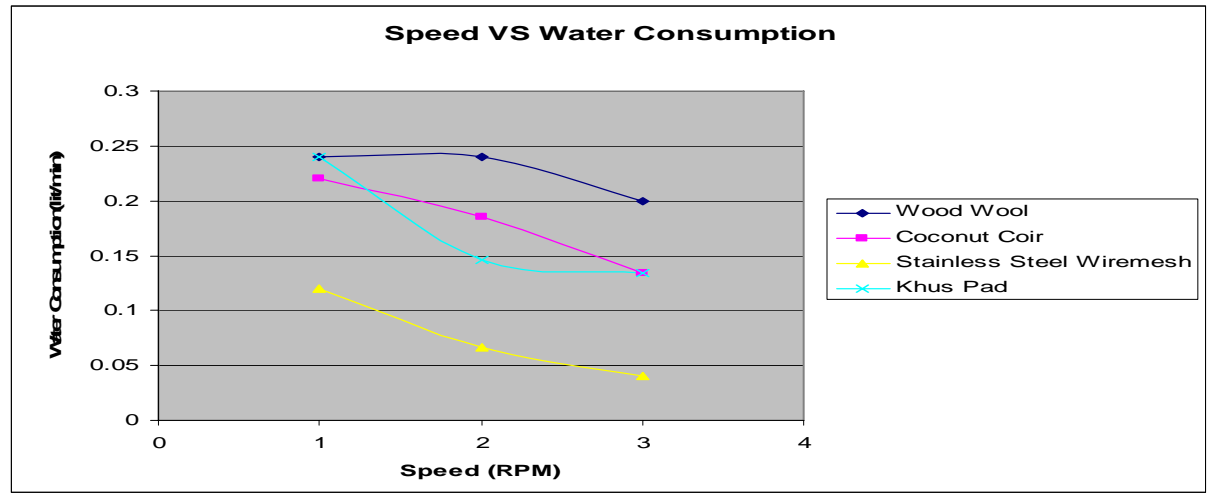

Fig: 2: Fan Speed vs. Water consumption 


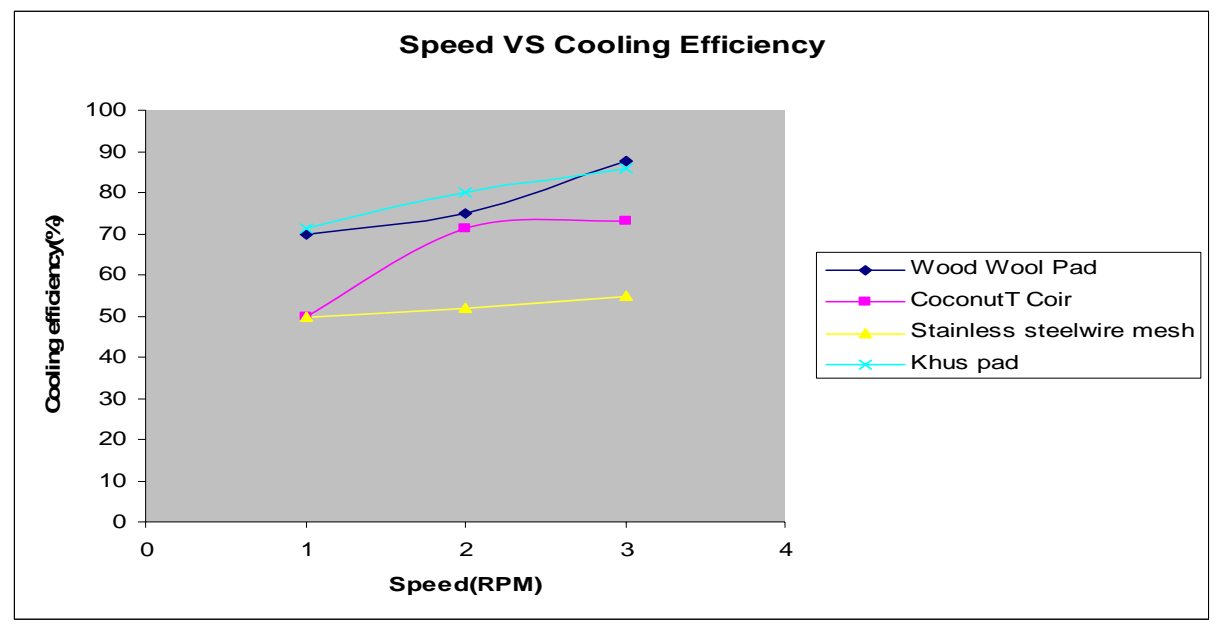

Fig: 3 Fan Speed vs. cooling efficiency

Fig 4 shows a variation of Fan speed vs. Air velocity. It reveals that resistance to air flow was higher at Khus pad as compared to wood wool and coconut coir pad. As a result wood wool pad and coconut coir pad shown higher air velocity which provides proper air distribution in room.

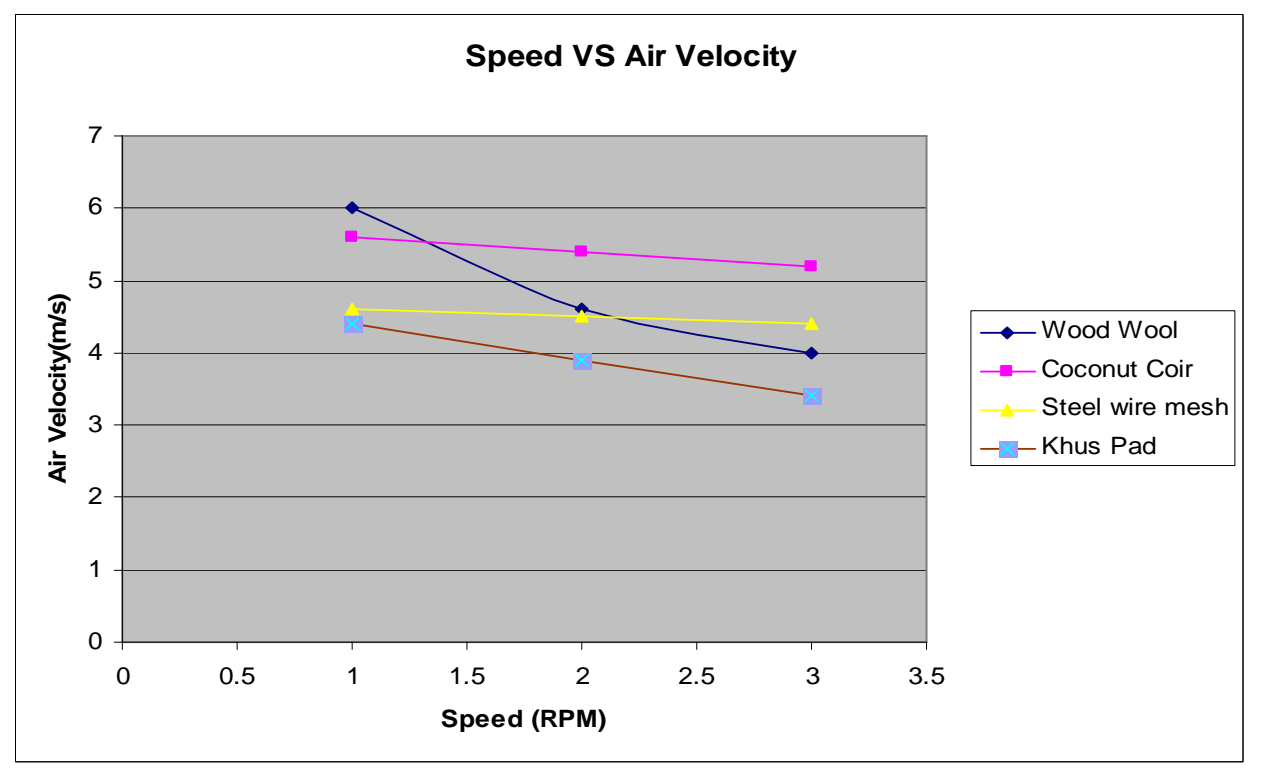

Fig: 4 Fan Seed vs. Air Velocity

CONCLUSION: A special test setup is designed to evaluate the performance of four materials to be used as wetted pads in evaporative cooling. The chosen materials are Wood wool, Coconuut coir, Khus and Stainless steel wire mesh. The performance criteria include cooling efficiency, air velocity and water consumption rate. The results show that the average cooling efficiency is highest for wood wool ( $87.5 \%$ ), compared to $75 \%$ for Khus pad, $71.42 \%$ for Coconut coir pad and $50 \%$ for Stainless steel wire mesh pad at same fan speed. But water consumption rate is higher for wood wool pad, as compared to Coconut coir, Khus and Stainless steel pad. Highest velocity of air was found in Coconut coir pad at same fan speed. Minimum water consumption was found in stainless steel wire mesh pad. 
ACKNOWLEDGMENTS: The author wish to thank G.H. Raisoni college of Engineering, Nagpur for the opportunity to carry out the experiments in the laboratory of Refrigeration and Air conditioning.

\section{REFERENCES}

1. Abdulla, K.N., Abdalla, A.M. and Al-Hashim, H.A. (1993). Utilization of Date Palm Leaves and Fibers as Wetted Pads in Evaporative Coolers. : Proceedings of the Third Symposium on the Date Palm, 2: 595601.

2. Bottcher, R.W., Baughman, G.R. and Kesler, D.J. (1989). Evaporative Cooling Using a Pneumatic Misting System. Transaction of the ASAE, 32, No. 2: 671-676.

3. B. Costelloe, D.P. Finn, (2005) .Thermal efficiency characteristics of indirect evaporative cooling systems. International Conference Passive and Low Energy Cooling for the Built Environment: Santorini, Greece, pp.549-554.

4. Faleh Al-Sulaiman, (2002). Evaluation of the performance of local fibers in evaporative cooling.
Energy Conversion and Management, Volume 43, Issue 16: pp. 2267-2273.

5. J.R.Camargo, (2008).Evaporative Cooling Water for Thermal Comfort. An Interdisciplinary Journal of Applied Science Vol 3,No4: pp.51-61

6. Koca, R.W., Hughes, W.C. and Christianson, L.L. (1991).Evaporative Cooling Pads Test Procedure and Evaluation. Applied Engineering in Agriculture, 7, No. 4: 485-490.

7. Mohammed A. Alodan and Abdulelah A. Al-Fara, .Design and Evaluation of Galvanized Metal Sheets as Evaporative Cooling Pads, J. King Saud Univ., Vol. 18, Agric. Sci. (1): pp. 9-18.

8. R. K. Kulkarni and S. P. S. Rajput, (2010). Theoretical performance analysis of jute fiber rope bank as media in evaporative coolers. Indian Journal of Science and Technology, Vol. 3 No. 10:pp 1075-1080

9. R. Rawangkul; J. Khedari; J. Hirunlabh; B. Zeghmati. (2008). Performance analysis of a new sustainable evaporative cooling pad made from coconut coir. International Journal of Sustainable Engineering, Volume $\underline{1}$, Issue $\underline{2}$ : pp. $117-131$. 